\title{
PERCEIVED INTRUSIVENESS IN DIGITAL ADVERTISING: LITERATURE REVIEW AND RESEARCH AGENDA
}

\author{
Vinod Madhavan \\ T A Pai Management Institute, \\ Manipal Academy of Higher Education, Karnataka, Manipal, India \\ Simon George \\ T A Pai Management Institute, Karnataka, Manipal, India
}

\begin{abstract}
Online advertising has gained tremendous traction in the past decade due to the explosive growth of internet and mobile connectivity. This has compelled marketers to look at different modes of advertising in the online space with high precision and positive outcomes. This paper conducts a literature review of existing constructs namely perceived intrusiveness within the extant body of knowledge to identify gaps and thus, provide new direction for research. The paper presents five major research areas in online advertising across different domains of business. It outlines potential areas of future research to throw more light on how organizations can adopt online advertising for building robust brands. It also seeks to provide inputs to industry practitioners and guide them to design strategies for effectively using rich media advertisements to reach out to their markets.
\end{abstract}

Key words: Perceived Intrusiveness, Brand Image, Online Advertisements, Rich Media Advertisements, Literature Review

Cite this Article: Vinod Madhavan and Simon George, Perceived Intrusiveness in Digital Advertising: Literature Review and Research Agenda, International Journal of Management, 11(12), 2020, pp 1918-1930.

http://iaeme.com/Home/issue/IJM?Volume=11\&Issue=12

\section{INTRODUCTION}

The current body of literature on online advertising and perceived intrusiveness derives its motivation from the vast number of studies in the area of traditional advertising. The concept of intrusiveness arises from the concept of privacy. Privacy is the right to be left alone (Warren and Brandeis, 1890). The emergence of the internet has led to some major concerns of privacy or maybe the intrusion of the privacy. The extant body of literature in traditional 
media clearly indicates the role of intrusiveness in causing consumer annoyance and consumer irritation (Bauer \& Greyser, 1968; Greyser, 1973). The tendency to avoid ads as much as possible through various behaviour is profound (Abernethy, 1990). Some consumers tend to shift their focus onto different things that may not be relevant to them (Krugman \& Johnson, 1991).

Intrusiveness is very likely to have influenced the online advertisements. Online ads were expected not to be very intrusive (Rust \& Varki, 1996). At times the online advertisements are also found be high on entertainment (Coyle \& Thorson, 2001). But users of internet have a different experience. Some of the users report ads as very disturbing (Reed, 1999) and some consumers experience strong emotions such as being annoyed (McCoy, Everald, Polak, \& Galletta, 2007), thereby resulting in distraction or deviation from expected experiences from online engagements. Some of the online ads normally push users into experiencing the advertisement passively without allowing scope for avoidance. The value of advertising hence falls due to user experience. However, Ducoffe (1995) argues that advertising value should be viewed from the overall value perceived by customers. Ducoffe's $(1995,1996)$ indicate the positive correlation between advertisement value and information value and entertainment value. He argues that for successful exchange of communication between consumers and advertisers it is essential to have high value information and entertainment. Edwards, Li and Lee (2002) posit that perceived intrusiveness of advertisements leads to higher levels of irritation and results in avoiding such advertisements. Intrusive advertisements are likely to affect attitudes and intentions toward the advertised brand and host Web site in a highly negative manner (Goodrich, Schiller and Galletta, 2015).

The definition of intrusiveness of ads assumes almost the same meaning. Ha (1996) described intrusiveness as "the degree to which advertisements in a media vehicle interrupt the flow of an editorial unit". Another definition made by Li et al. (2002) refers to the cognitive process. Li et al (2002) state that it is important to consider intrusiveness as a cognitive process and not the reactions and negative behaviour that occur as an effect of it. It is not the intrusiveness itself that creates the negative feelings and behaviour but rather something that describes the mechanism that leads to reactance and negative behaviour and feelings. Ying, Korneliussen and Grønhaug (2009) posited that perceived intrusiveness can be moderated by the degree of value generated and better placement and execution.

Studies based on pop up ads in experiments have reveals formation of negative attitudes and reactance from the consumers resulting in ad avoidance and feeling of irritation (Cho and Cheon 2004, Edwards, Li and Lee 2002). Increasing relevance was found to increase reactance (Edwards, Lee and $\mathrm{Li}$ 2002). If an ad is relevant, then it cannot be easily dismissed as meaningless. Intrusiveness and irritation are lessened by information that are very meaningful. Hence in this context content placement assumes significance in making the ads relevant (Janiszewski 1990; Yi 1990). This is specifically the case in television advertisements (Murry, Lastovicka, and Singh 1992; Park and McClung 1986; Singh and Churchill 1987; Soldow and Principe 1981).

Online browsers and buyers are goal directed in their approach. Any form of disruption in a goal directed activity could be considered as intrusive and there is a frequent complaint against the different advertising practices that are being used (Li, Edwards \& Lee, 2002). Bauer and Greyser (1968) found that intrusiveness is an important factor to explain advertising annoyance. The magnitude of the perceived intrusiveness could result in feelings of irritation ( $\mathrm{Li}$ et al., 2002). The more the ads interfere, the higher will the level of intrusiveness be.

The emergence of technology that allows online ads to surface wherever and whenever during the surfing sessions have made it challenging for online viewers. This makes it 
possible to expose the consumers to unexpected ads and this might affect the perceived intrusiveness. This leads to two possible outcomes which will define intrusiveness. One whether the ad is preventing the consumer from doing what $\mathrm{s} / \mathrm{he}$ is doing. Two, whether it is possible to close the ad or not. Annoying advertisements play a mediating role between perceived intrusiveness and avoidance (Petrovici, Marinova \& Marinov,2017)

Repeated pop-ups in large numbers at frequent intervals has a negative effect on the consumer (Ying et al.2009). Truong and Simmons (2010) studied the perceived intrusiveness in digital advertising and states that internet advertisements could be considered as both helpful and misleading. Helpful advertisements provide the consumer with objective sources of information (Truong \& Simmons, 2010). Ying et al. (2009) support this principle in the way that ads that provide the consumer with either useful information or entertainment are perceived to be less intrusive than the ones that are not. Larger ads in terms of size were perceived as more intrusive than smaller ones. However, ads with sounds were not found to be more intrusive than the ones without (Ying et al., 2009). Edwards et al (2002) posited that ads of high relevance decrease the risk of intrusiveness. In a study on mobile location-based advertising, Gutierrez et al (2019) identified intrusiveness as one of the most significant risk factor to determine the intentions of mobile phone users in acceptance of the advertisements.

An important aspect that could limit the intrusiveness is if it gives value. Truong \& Simmons (2010) reported the misleading advertisements that were said to favour the customer turned out to be non-existent. Examples of this are advertisements with incorrect information about the product and services and banners and pop ups that leads to products and services that in the end were not available for the advertised price.

Brand advertisement rankings are also an important factor in online advertising. Top ranked keyword search ads for a brand that is relatively unknown generates far greater recognition and hence a stronger brand evaluation (Chan Yun Yoo 2014). The author posits the use of keyword ads as less intrusive leading to more favourable evaluations of an unknown brand.

Edwards, Li and Lee (2002) in their paper argue that online ads are avoided when they are perceived to be intrusive. The avoidance behaviour is an outcome of irritation caused due to disruption in the viewing and internalizing of the editorial content. However, the authors also report the effect of intrusiveness to be low if the ads are entertaining or informative. McCoy et al (2008) used intrusiveness in predicting how consumers directly relate to ad recognition. Hühn et al (2017) argue that the level of cognitive effort of the consumer influences the degree of intrusiveness, relevance and value of an location based advertisement in smartphones. In the case of social marketing and advertising communications, consumers perceived the online advertisements promoted by marketers to be more intrusive than the ones forwarded by users of Facebook (Morris, Choi and $\mathrm{Ju}, 2016$ ). Zha and $\mathrm{Wu}$ (2014) demonstrated that advertisements that are disruptive by nature are perceived to be highly intrusive and annoying which builds negativity at the affect level.

The paper presents a comprehensive literature review to identify inconsistencies and gaps in existing research. Existing contributions in perceived intrusiveness and brand image were collected, analysed, and aligned with online advertising concepts with an aim to address the following:

What are the emerging areas in online advertising with respect to brand building?

What are the new areas of research in devising online advertisement plans using tools such as rich media advertisements? 
The rest of the paper is organized as follows: Section 2 provides the research method; Section 3 presents the analysis; and Section 4 provides the areas of future research and summarizes the conclusions.

\section{RESEARCH METHOD}

Literature reviews are conducted to identify areas for future research with the aim to further develop theory (Webster and Watson, 2002; Garza-Rayes, 2015; Padalkar and Gopinath, 2015; Wahyono, 2018). Literature review adopts a process that is both reproducible and systematic (Fink, 2005). Accordingly, we conduct a systematic study of extant literature to address the research questions listed in the previous section. Denyer and Transfield (2009) list out the following steps for a systematic review: (1) forming the research question; (2) listing various studies; (3) selecting and evaluating the study; (4) analysing it; and (5) reporting the results. Sections 1, 3 and 4 cover stages one and five while the sections that follow cover phases 2, 3 and 4. Saunders et al. (2012) highlight the need for transparency by detailing how the review was conducted. Fig 1 illustrates different phases of the literature review, along with the sections.

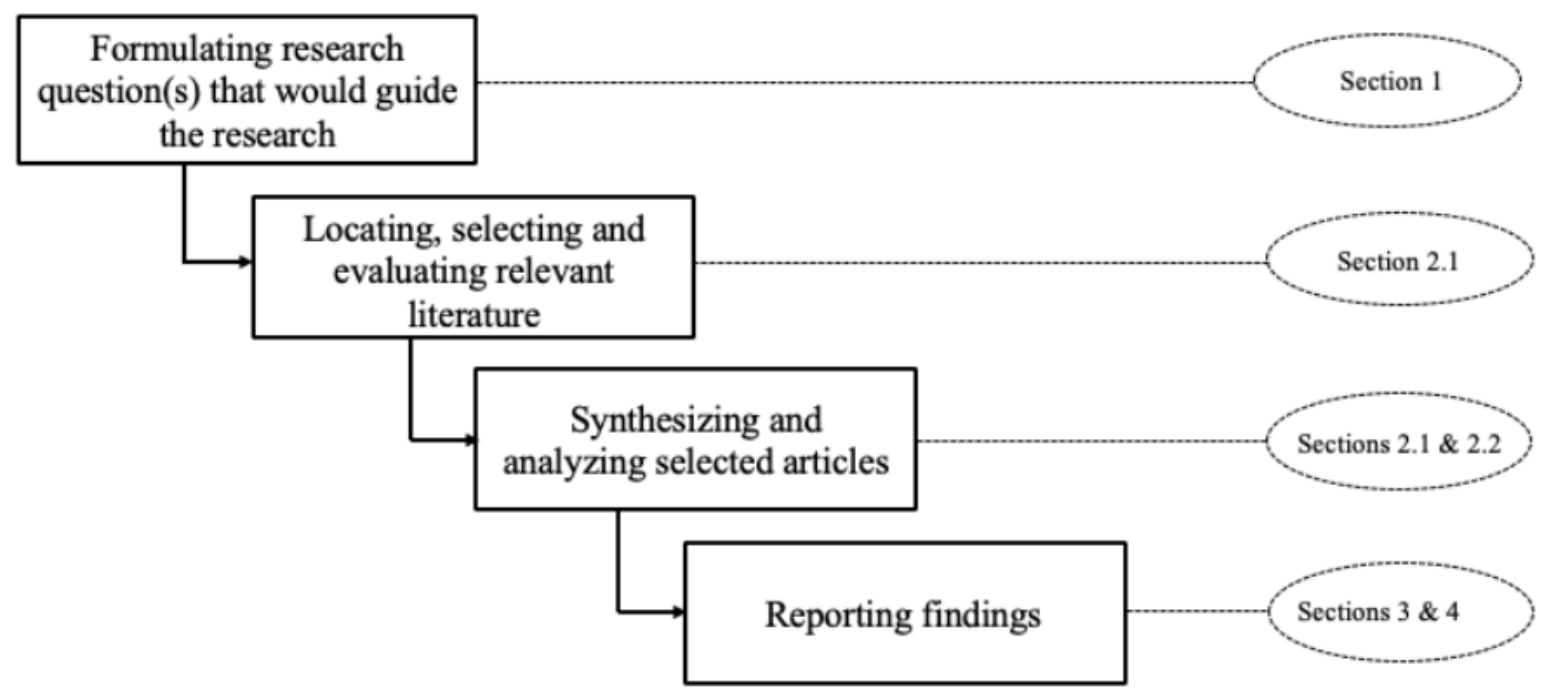

Figure 1 Stages of systematic literature review

\subsection{Literature Selection}

The articles were identified using various search criteria to list relevant publications. The databases included Emerald, Elsevier, IEEE, Springer, Inderscience and Wiley. Additionally, we also referred to Google Scholar and EBSCO. The overlap identified with the listed databases helped to validate the earlier search criteria to ensure that all relevant articles were considered.

The key question that arises is how does an online advertiser achieve his/her marketing goal without angering the customer? This poses the biggest challenge for online advertisers wherein they must achieve their marketing goals while avoiding consumer anger or distrust. Edwards, Li, and Lee (2002) have argued that intrusive advertisements interfere with navigation and browsing activities and this leads to internet users reacting with strong irritation and also high propensity to avoid ads This document was used as a reference to define the research period for this study, that is, 2002 to 2019. 
The search criteria for the articles were based on the areas defined for the current research. The CIMO framework was adopted during this phase. The search criteria included search words, such as perceived intrusiveness, brand image, online advertising, banners, interstitials and rich media ads. This helped us to focus on a specific search criterion and exclude articles which either did not include both the terms or demonstrated a relationship between them. This approach helped to ensure that our literature study was comprehensive. In addition, manual checks were undertaken to eliminate articles that did not align perceived intrusiveness and brand image or were outside the scope of the timeline selected for this study. After the elimination, we were left with 124 articles which we uploaded on the QSR NVivo software for further analysis. This software is considered as the most effective for this type of analysis (Thorpe et al., 2005; Thomas and Harden, 2008).

\subsection{Analysis and Synthesis}

Several methods are used to undertake the synthesis of qualitative research such as qualitative comparative examination, grounded theory, thematic synthesis, and content analysis. This research uses the thematic synthesis owing to its efficiency in recognizing recurrent themes (Tong et. al., 2012). Using this approach, we categorized the selected articles into three groups (Fig 2). The first group consisted of articles that studied lean and green conceptually, while articles in the remaining two groups focussed on process/operations and supply chain, respectively. Groups two and three were each further categorised as core and extended level (Fig 2), respectively. The identified 124 articles were assigned to the defined categories.

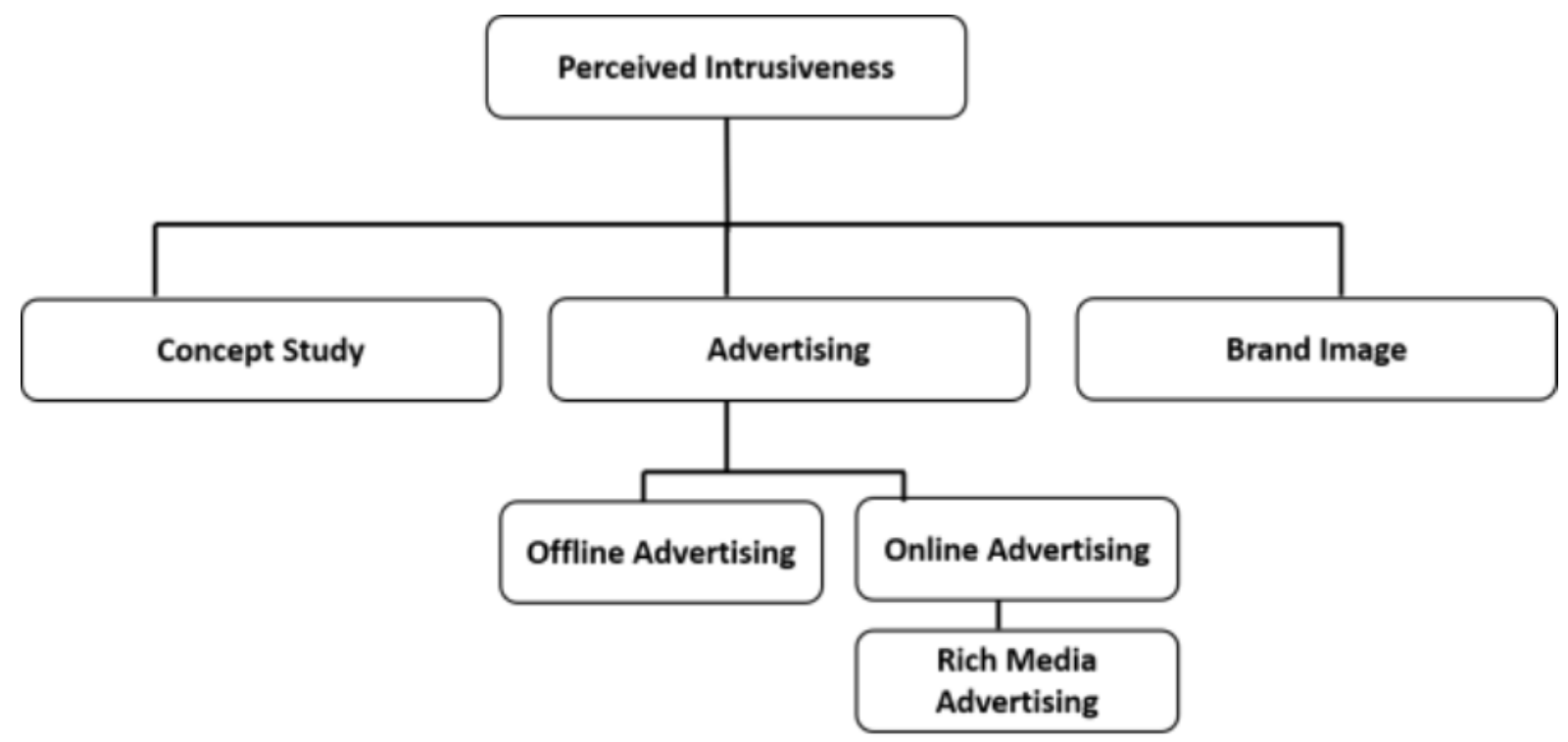

Figure 2 Grouping of articles

Section 3 details the findings from the thematic synthesis.

\section{ANALYSIS}

\subsection{Descriptive Analysis}

There were 124 articles $(n=124)$ that aligned with the defined search criteria and related to perceived intrusiveness, brand image, online advertising, and rich media ads.

\subsubsection{Publications Analysis}

Figures 3 to 6 detail the publication sources of the articles selected for the study, including journals and conferences. They also provide information on articles per database and 
published per year. According to the results, online advertising began to generate immense interest in the research fraternity after the year 2000; $90 \%$ of the articles were published 2000 onwards. The higher interest in this area can largely be attributed to the increase in internet connectivity and migration from offline to online purchases due to increasing consumer awareness. As a result, this area of research is expected to develop further and attract more research (Chan Yun Yoo 2014)

\subsubsection{Classification of Publications}

The papers were initially categorised based on the macro and micro levels (Section 2.2) and then further into core and additional elements to identify possible similarities to aid the analysis process (Fig 2). Extant literature demonstrates that the current body of literature on online advertising and perceived intrusiveness derives its motivation from the vast number of studies in the area of traditional advertising. This is evident from the articles listed in the search, which focus on both perceived intrusiveness and brand image as evident in the offline and online advertisement research. Thirty-seven percent of the articles considered perceived intrusiveness as an important element in advertisements along with other concepts, such as annoying (McCoy, Everald, Polak, \& Galletta, 2007), misleading (Truong and Simmons, 2010), brand evaluation (Chan Yun Yoo 2014), brand image (Lange and Dahle'n, 2003) and ad avoidance (Cho and Cheon,2004). This lends credence to the fact that researchers have looked at intersecting strategic initiatives with perceived intrusiveness and brand image. About twenty five percent of the articles discussed brand image and perceived intrusiveness conceptually in terms of negative outcomes, impact on brand image and the theoretical implications.

\subsubsection{Categorization of Articles}

Since the search criteria were based on perceived intrusiveness and brand image, thematic analysis, along with categorisation, (Fig 2) brought to light other focus areas. The concept map helped to categorize the articles and set base to discuss the findings. Also, the articles were mapped to their respective categories on their area of focus. This helped to provide clarity on how many category-wise articles were published.

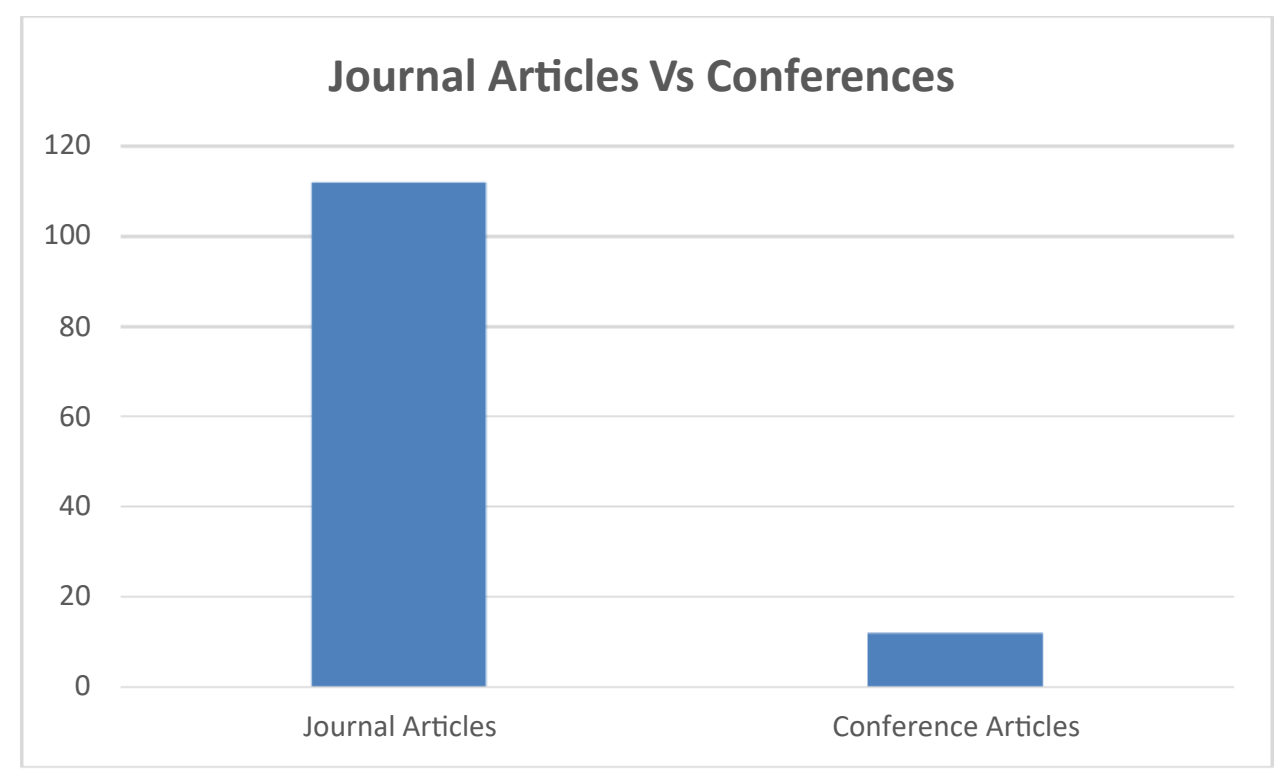

Figure 3 Comparison of journals vs conferences 


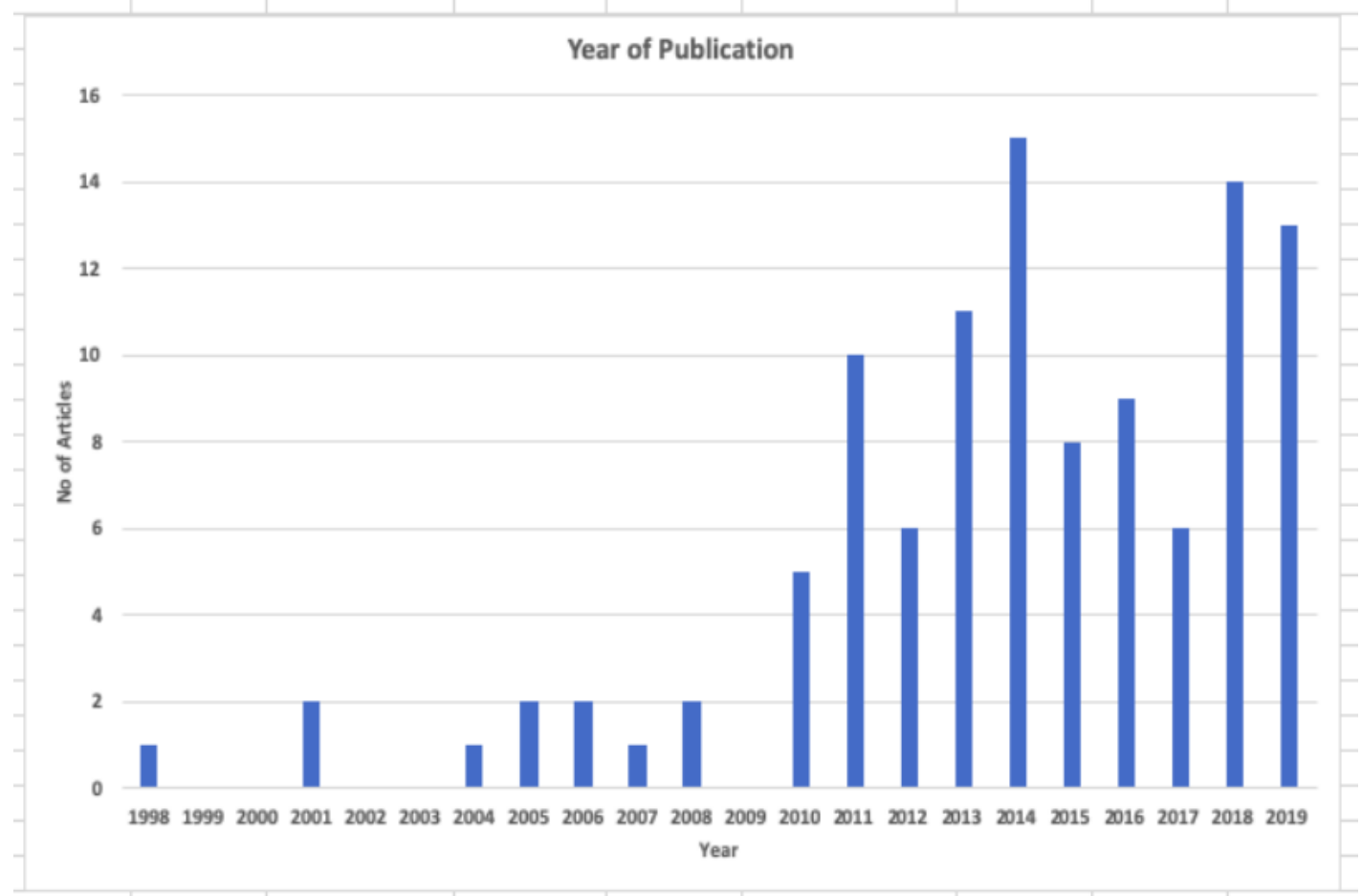

Figure 4. Year of publication

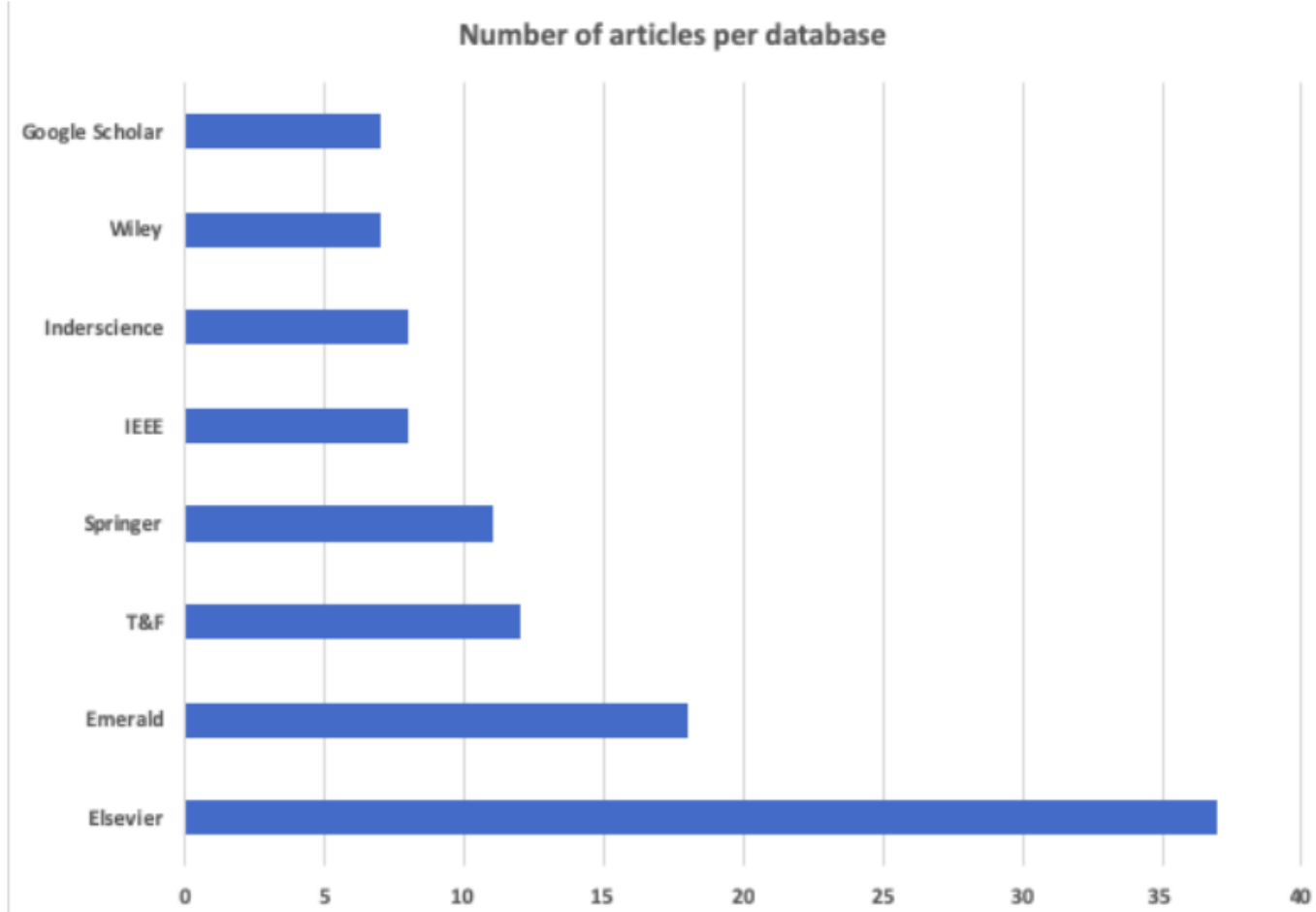

Figure 5 Publications count per database

The categorization outlines five categories under which the articles were grouped. Annexure 1 outlines the details of these articles considered for this grouping. These categories include integration, study alongside, compatibility, empirical application, impact on brand image and challenges in online advertising. These categories were defined based on thematic contents of the selected articles. Some of these categories also had subcategories to provide more clarity. All the articles listed under their respective categories are represented in the 
concept map. These also include cross-referenced articles, which found reference to more than one category. The categories are discussed in detail in Sections 3.2 to 3.8

\subsection{Perceived Intrusiveness and Brand Image: Integration}

While some studies have explained the antecedents and consequences of perceived intrusiveness of online advertisements, there seems to be a strong ambiguity on the outcome of such intrusiveness. Whether perceived intrusiveness has any impact on brand image is not explored yet. With a large amount of advertisements online, various brands are being thrust into the online space to gain the consumers attention. A strongly proven concept in the brand literature is the outcome of highly consistent and highly cohesive brand image guiding consumers understanding and prediction on the brand standing in the market (Erdem and Swait 1998; Keller 1999; Lange and Dahle'n 2003). Kim et al (2013) posited that websites in the business of streaming videos, movies and television programs risk higher perceived intrusiveness of advertisements leading to ad avoidance behaviour and finally resulting in negative attitude towards advertising. Marketers are attempting to customize advertisements to consumer requirements thereby focusing on stronger purchase intentions without creating higher levels of perceived intrusiveness (Doorn and Hoekstra, 2013)

\subsection{Application of the Perceived Intrusiveness in Online Context}

Any online-advertisement information combined with entertainment and lack of irritation tends to increase an advertisement's perceived value (Ducoffe, 1996. Intrusiveness also can have potentially negative effects for brands, as diminished visitor attitudes and revisit intentions (McCoy et al., 2008) lead to lower site traffic, threatening future advertising revenue. Morimoto and Chang (2013) posited that specific consumers who receive unsolicited e-mails perceive it as highly intrusive and irritating. Riedel, Weeks and Beatson (2018) identified three key drivers of intrusiveness namely temporal disruption, visual disruption and flow disruption leading to emotional response, behavioural response and cognitive response. While there are strong arguments on ad irritation, the impact of irritation on the advertised brand online is not well defined. Perceived intrusiveness of advertisements also has major implications in the domain of strategic marketing specifically in the online context of push or pull approach (Truong \& Simmons, 2010). In mobile advertising, higher the availability of information lesser is the perceived intrusiveness (Wang,Oh and Wang,2009)

\subsection{Empirical Application}

Seventy three percent of articles related to the internet research were quantitative in nature (Cho and Khang, 2006). Qualitative research methods were used by twenty seven percent. Evaluation of online advertising researches (Ha,2008), reported the robustness of quantitative research methods in empirical studies in online advertising. Further the higher rate of acceptance in scholarly journals was closely related to the quantitative methodologies used with intensive use of statistical testing and stronger ability to achieve generalization of the results. Li,Edwards and Lee (2013) developed a scale by reducing the number of items statistically and thereby constructed a new approach for measuring intrusiveness lending a robust approach to more quantitative studies.

\subsection{Impact on Brand Image}

Research of traditional media indicates various emotions such as irritation when the advertisements are highly intrusive in nature. (Kennedy, 1971; Krugman, 1983; Soldow \& Principe, 1981). Negative outcomes such as irritation or ad avoidance are due to distraction or interruption of goal-based tasks. (Aaker \& Bruzzone, 1985). Irritation being a negative 
emotion has certain impact on the brand image. McCoy et al (2017) used intrusiveness as an intervening variable to demonstrate the drop in perception with higher number of impressions towards website attitudes and intentions. Guardia and Lopez (2014) argue that high levels of perceived intrusiveness result in reduced impact of advertisements and a reduction in positive attitude towards the brand. The effect of ad irritation on brand image is not explored in the current literature.

\subsection{Challenges in Online Advertising}

Jensen (2006) highlights out three different types of online advertising. The first type of advertising is display advertising in the form of banners, pop-ups and interstitials. The second type of advertising is in the form of search engine optimization (SEO) or search engine marketing (SEM) that could be both organic and paid optimization. The third type of advertising is affiliate programs. An affiliate program works on the lines of a multimedia ad wherein a marketer places an ad or a link on the desired website to direct the consumer to them and whenever someone clicks on the link the host will get a commission for it. The customer has the freedom to bypass any of these ads and off late the tendency to bypass online ads in increasing and is matter of concern to advertisers. Online browsers and buyers are goal directed in their approach. Any form of disruption in a goal directed activity could be considered as intrusive and there is a frequent complaint against the different advertising practices that are being used (Li, Edwards \& Lee, 2002). Bauer and Greyser (1968) found that intrusiveness is an important factor to explain advertising annoyance. The magnitude of the perceived intrusiveness could result in feelings of irritation ( $\mathrm{Li}$ et al., 2002). The more the ads interfere, the higher will the level of intrusiveness be.

The emergence of technology that allows online ads to surface wherever and whenever during the surfing sessions have made it challenging for online viewers. This makes it possible to expose the consumers to unexpected ads and this might affect the perceived intrusiveness. This leads to two possible outcomes which will define intrusiveness. One whether the ad is preventing the consumer from doing what $\mathrm{s} /$ he is doing. Two, whether it is possible to close the ad or not.

Repeated pop-ups in large numbers at frequent intervals has a negative effect on the consumer (Ying et al.2009). Truong and Simmons (2010) studied the perceived intrusiveness in digital advertising and states that internet advertisements could be considered as both helpful and misleading. Ying et al. (2009) support this principle in the way that ads that provide the consumer with either useful information or entertainment are perceived to be less intrusive than the ones that are not. Larger ads in terms of size were perceived as more intrusive than smaller ones. Perceived autonomy decreases the perception of ad intrusiveness (Youn and Kim, 2019). Subsequently, ad intrusiveness and freedom threat to use Facebook have a positive effect on reactance, which influences ad avoidance Addressing these challenges could aid in implementing powerful online advertisements across different businesses.

\subsection{Areas for Future Research}

Sections 3.2 to 3.7 outline various streams of research related to lean and green concepts. Majority of the articles researching online advertising have been published since 2010. Seventy three percent of the articles employed empirical techniques. Some of the streams outlined have been explored in detail while others need more study.

This section describes various questions that can be further studied based on observations made in the previous sections. Marx (1997) and Bell et al. (2018) have highlighted the need to 
formulate research questions that can guide future research. Accordingly, Table 1 lists the questions that can guide future research.

Table 1 Areas for future research

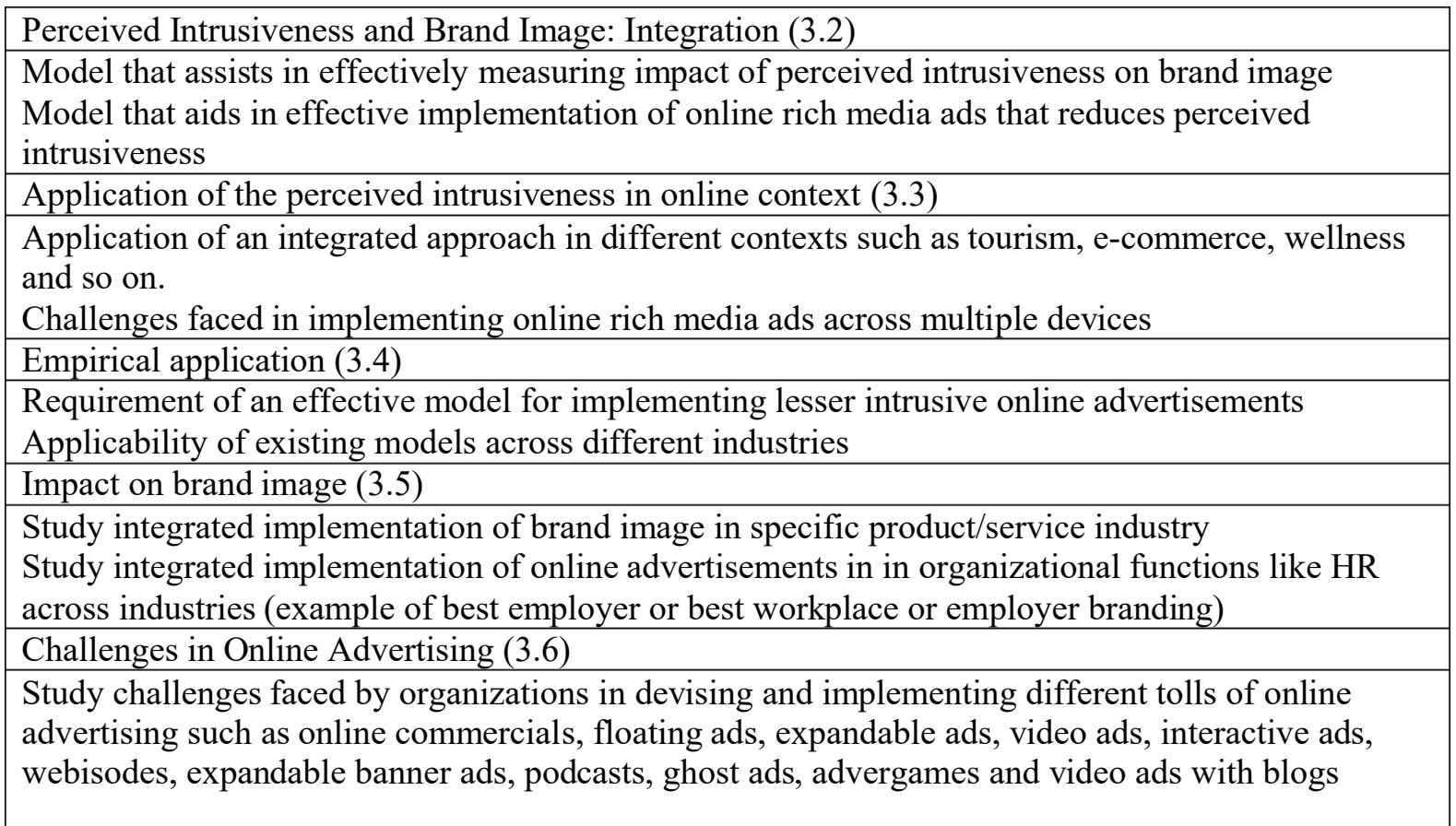

\section{CONCLUSION}

As technology seeps into every aspect of our life, it is imperative to understand the newer methods of reaching out to consumers through online advertisements that are targeted with precision. However, marketers must continue to seek newer ways of reaching out to their consumers without any perception of perceived intrusiveness. This paper attempts to conduct a literature review on perceived intrusiveness and brand image concepts and identify future areas of study in this context.

This study has also classified five research streams in the online advertising domain. These streams are broad but not exhaustive. Research scholars can consider these research streams and explore specific gaps in the extant literature. Findings will contribute to the body of knowledge.

Additionally, this study can also be used by industry practitioners to gain insights into online advertising and use them in practice.

\section{REFERENCES}

[1] Aaker, D.A. and Bruzzone, D.E. Causes of irritation in advertising. Journal of marketing, 49(2), 1985, pp.47-57.

[2] Bauer, R.A. and Greyser, S.A. (1968), "Advertising in America: The Consumer View", Boston, MA: Harvard University

[3] Cho, C.H. and as-, U.O.T.A.A.I.A. Why do people avoid advertising on the internet? Journal of advertising, 33(4), 2004, pp.89-97.

[4] Cho, C.H. and as-, U.O.T.A.A.I.A., Why do people avoid advertising on the internet?. Journal of advertising, 33(4), 2004, pp.89-97. 
[5] Cho, C.H. and Khang, H. The state of internet-related research in communications, marketing, and advertising: 1994-2003. Journal of Advertising, 35(3), 2006, pp.143-163.

[6] Coyle, J.R. and Thorson, E. The effects of progressive levels of interactivity and vividness in web marketing sites. Journal of advertising, 30(3), 2001, pp.65-77.

[7] Ducoffe, R.H. How consumers assess the value of advertising. Journal of Current Issues \& Research in Advertising, 17(1), 1995, pp.1-18.

[8] Ducoffe, R.H. Advertising value and advertising on the web. Journal of advertising research, 36(5),1996, pp.21-21.

[9] Edwards, S.M., Li, H. and Lee, J.H. Forced exposure and psychological reactance: Antecedents and consequences of the perceived intrusiveness of pop-up ads. Journal of advertising, 31(3), 2002, pp.83-95.

[10] Erdem, T. and Swait, J. Brand equity as a signaling phenomenon. Journal of consumer Psychology, 7(2), 1998, pp.131-157.

[11] Goodrich, K., Schiller, S.Z. and Galletta, D. Consumer reactions to intrusiveness of onlinevideo advertisements: do length, informativeness, and humor help (or hinder) marketing outcomes?. Journal of Advertising Research, 55(1), 2015, pp.37-50.

[12] Greyser, S.A. Irritation in advertising. Journal of Advertising Research, 13(1), 1973, pp.3-10.

[13] Gutierrez, A., O'Leary, S., Rana, N.P., Dwivedi, Y.K. and Calle, T. Using privacy calculus theory to explore entrepreneurial directions in mobile location-based advertising: Identifying intrusiveness as the critical risk factor. Computers in Human Behavior, 95, 2019, pp.295-306.

[14] Ha, L. Advertising clutter in consumer magazines: Dimensions and effects. Journal of advertising research, 36(4),1996, pp.76-85.

[15] Rotfeld, H.J., Abernethy, A.M. and Parsons, P.R. Self-regulation and television advertising. Journal of Advertising, 19(4), 1990, pp.18-26.

[16] Hühn, A.E., Khan, V.J., Ketelaar, P., van't Riet, J., Konig, R., Rozendaal, E., Batalas, N. and Markopoulos, P. Does location congruence matter? A field study on the effects of locationbased advertising on perceived ad intrusiveness, relevance \& value. Computers in Human Behavior, 73, 2017, pp.659-668.

[17] Janiszewski, C. The influence of print advertisement organization on affect toward a brand name. Journal of consumer research, 17(1), 1990, pp.53-65.

[18] Jensen, M.B. and Jepsen, A.L. Online marketing communications: need for a new typology for IMC?. Journal of Website promotion, 2(1-2), 2008, pp.19-35.

[19] Keller, K.L. Managing brands for the long run: brand reinforcement and revitalization strategies. California management review, 41(3), 1999, pp.102-124.

[20] Kennedy, J.R. How program environment affects TV commercials. Journal of Advertising Research, 11(1), 1971, pp.33-38.

[21] Kim, E., Choi, S.M., Kim, S. and Yeh, Y.H. Factors affecting advertising avoidance on online video sites. The Journal of Advertising and Promotion Research, 2(1), 2013, pp.87-121.

[22] Krugman, D.M. and Johnson, K.F. Differences in the consumption of traditional broadcast and VCR movie rentals. Journal of Broadcasting \& Electronic Media, 35(2), 1991, pp.213-232.

[23] Krugman, H.E., 1983. Television program interest and commercial interruption. Journal of Advertising Research.

[24] Lange, F. and Dahlén, M., 2003. Let's be strange: brand familiarity and ad-brand incongruency. Journal of Product \& Brand Management. 
[25] Li, H., Edwards, S.M. and Lee, J.H. Measuring the intrusiveness of advertisements: Scale development and validation. Journal of advertising, 31(2), 2002, pp.37-47.

[26] McCoy, S, Everard, A, Polak, P and Galletta, D.The Effects of Online Advertising, Communications of the ACM - Emergency response information systems: emerging trends and technologies, Volume 50 (3),2007, pp.84-88

[27] McCoy, S., Everard, A., Galletta, D.F. and Moody, G.D. Here we go again! The impact of website ad repetition on recall, intrusiveness, attitudes, and site revisit intentions. Information \& Management, 54(1), 2017, pp.14-24.

[28] McCoy, S., Everard, A., Polak, P. and Galletta, D.F. An experimental study of antecedents and consequences of online ad intrusiveness. Intl. Journal of Human-Computer Interaction, 24(7), 2008, pp.672-699.

[29] Morimoto, M. and Chang, S. Consumers' attitudes toward unsolicited commercial e-mail and postal direct mail marketing methods: intrusiveness, perceived loss of control, and irritation. Journal of Interactive Advertising, 7(1), 2006, pp.1-11.

[30] Morris, J.D., Choi, Y. and Ju, I. Are social marketing and advertising communications (SMACs) meaningful?: A survey of Facebook user emotional responses, source credibility, personal relevance, and perceived intrusiveness. Journal of Current Issues \& Research in Advertising, 37(2), 2016, pp.165-182.

[31] Murry Jr, J.P., Lastovicka, J.L. and Singh, S.N. Feeling and liking responses to television programs: An examination of two explanations for media-context effects. Journal of consumer research, 18(4), 1992, pp.441-451.

[32] Park, C.W. and McClung, G.W., 1986. The effect of TV program involvement on involvement with commercials. ACR North American Advances.

[33] Petrovici, D.A., Marinova, S.T. and Marinov, M.A., 2017. Perceived advertising intrusiveness and avoidance in emerging economies: The case of China. In Research Handbook of Marketing in Emerging Economies. Edward Elgar Publishing.

[34] Austin, M.J. and Reed, M.L., 1999. Targeting children online: Internet advertising ethics issues. Journal of Consumer Marketing.

[35] Rejón-Guardia, F. and Martínez-López, F.J., 2014. Online advertising intrusiveness and consumers' avoidance behaviors. In Handbook of strategic e-business management (pp. 565586). Springer, Berlin, Heidelberg.

[36] Riedel, A.S., Weeks, C.S. and Beatson, A.T. Am I intruding? Developing a conceptualisation of advertising intrusiveness. Journal of Marketing Management, 34(9-10), 2018, pp.750-774.

[37] Rust, R.T. and Varki, S. Rising from the ashes of advertising. Journal of Business Research, 37(3),1996, pp.173-181.

[38] Singh, S.N. and Churchill Jr, G.A. Arousal and advertising effectiveness. Journal of Advertising, 16(1), 1987, pp.4-40.

[39] Soldow, G.F. and Principe, V., 1981. Response to commercials as a function of program context. Journal of Advertising Research.

[40] Truong, Y. and Simmons, G. Perceived intrusiveness in digital advertising: strategic marketing implications. Journal of strategic marketing, 18(3), 2010, pp.239-256.

[41] Van Doorn, J. and Hoekstra, J.C. Customization of online advertising: The role of intrusiveness. Marketing Letters, 24(4), 2013, pp.339-351.

[42] Wang, T., Oh, L.B. and Wang, K., 2009, November. Antecedents and consequences of mobile advertising intrusiveness. In the 9th International Conference on Electronic Business. Macau, China. 
[43] Warren, S.D. and Brandeis, L.D. The right to privacy. Harvard law review, 1890, pp.193-220.

[44] Yi, Y. A critical review of consumer satisfaction. Review of marketing, 4(1), 1990, pp.68-123.

[45] Ying, L., Korneliussen, T. and Grønhaug, K. The effect of ad value, ad placement and ad execution on the perceived intrusiveness of web advertisements. International Journal of Advertising, 28(4), 2009, pp.623-638.

[46] Yoo, C.Y. Branding potentials of keyword search ads: The effects of ad rankings on brand recognition and evaluations. Journal of Advertising, 43(1), 2014, pp.85-99.

[47] Youn, S. and Kim, S. Understanding ad avoidance on Facebook: Antecedents and outcomes of psychological reactance. Computers in Human Behavior, 98, 2019, pp.232-244.

[48] Zha, W. and Wu, H.D. The Impact of Online Disruptive Ads on Users' Comprehension, Evaluation of Site Credibility, and Sentiment of Intrusiveness. American Communication Journal,16(2), 2014, pp.112-131 